\author{
УДК 330:651.5:657 \\ ОРГАНИЗАЦИЯ ЭЛЕКТРОННОГО ДОКУМЕНТООБОРОТА ДЛЯ УПРАВЛЕНИЯ \\ ДЕБИТОРСКОЙ ЗАДОЛЖЕННОСТЬЮ \\ Татьяна Н. Павлюченко ${ }^{a,{ }^{\prime},}$; Ирина В. Калюгина ${ }^{a}$ \\ а Воронежский государственный аграрный университетимени императора Петра I, 394087, Россия, \\ 2. Воронеж, ул. Мичурина, 1 \\ @Pavlychenkotn@mail.ru \\ ID https://orcid.org/0000-0002-9879-1079
}

Поступила в редакциюю 03.11.2018. Принята к печати 26.11.2018.

Ключевые слова:

бизнес-процесс, контроль, бухгалтерская служба, электронный архив, деловые коммуникации

\begin{abstract}
Аннотация: Приоритетной целью большинства компаний в процессе формирования финансовой информации о наличии и движении дебиторской задолженности является сокращение времени на ее подготовку без потери качества. Поставленная цель может быть достигнута посредством оптимизации бизнес-процессов, одним из направлений которой может выступать электронный документооборот. Внедрение электронного документооборота позволит существенно сократить сроки обработки договоров, одновременно обеспечивая приемлемую полноту и достоверность информации. Контролировать дебиторскую задолженность и оперативно реагировать на возникновение просроченных долгов позволит ежедневный отчет, формируемый в автоматическом режиме. В статье рассмотрен процесс внедрения системы электронного документооборота, подчеркивается эффективность и целесообразность его применения в процессе подготовки информации о расчетах с дебиторами. Одним из ключевых обстоятельств является то, что после успешного прохождения всех этапов автоматизации внедренная система должна постоянно дорабатываться и совершенствоваться. Это является одним из основных факторов успешного использования электронного документооборота для управления дебиторской задолженностью.
\end{abstract}

Для цитирования: Павлюченко Т. Н., Калюгина И. В. Организация электронного документооборота для управления дебиторской задолженностью // Вестник Кемеровского государственного университета. Серия: Политические, социологические и экономические науки. 2018. № 4. C. 107-112. DOI: 10.21603/2500-33722018-4-107-112

\section{Введение}

Дебиторская задолженность возникает из-за временного разрыва между операцией купли-продажи товаров, работ или услуг и их оплатой. Работа с дебиторской задолженностью требует четко выстроенного и спланированного процесса управления риском неплатежей. К наиболее распространенным проблемам, связанным с управлением дебиторской задолженностью, которые характерны для большей части предприятий, можно отнести следующие:

1) отсутствие достоверной информации о сроках погашения дебиторами своих обязательств перед организацией;

2) отсутствие внутреннего регламента по работе с просроченной дебиторской задолженностью;

3) отсутствие контроля за оборачиваемостью дебиторской задолженности, а также о величине затрат, связанных с увеличением ее размера;
4) отсутствие оценки кредитоспособности покупателей и заказчиков на стадии подписания договора;

5) отсутствие регламента взаимодействия между различными подразделениями организации, осуществляющими функции сбора денежных средств, анализа дебиторской задолженности, и, как следствие, отсутствие ответственных за каждый этап.

Основные факторы, определяющие, почему контрагенты не оплачивают свою задолженность в установленные сроки, можно объединить в 5 групп.

1 группа. Наиболее актуальными в современных условиях являются факторы экономического характера. Дебитор временно испытывает дефицит оборотных средств в связи с кризисными процессами, происходящими на рынке, и не может своевременно исполнить долговые обязательства.

2 группа. Дебитор располагает достаточным количеством денежных средств, согласен произвести 
оплату, но в то же время не платит вовремя вследствие монопольного положения на рынке или значительного перевеса в экономическом потенциале. Данная ситуация может возникать из-за особенностей финансовой стратегии должника, который предпочитает расширять свой бизнес за счет временно привлеченных средств.

3 группа. Обстоятельства категории «Форс-мажор». В качестве таких факторов могут выступать природные катаклизмы, стихийные бедствия, аварии, техногенные катастрофы, вмешательство компетентных органов.

4 группа. К факторам данной группы относят причины недобросовестного характера, когда должник изначально не собирается осуществлять оплату за приобретенные ценности или полученные услуги. В качестве предпосылок могут быть выделены наличие просчетов в подписанном соглашении, наличие законодательных «ловушек», отсутствие достаточного контроля над расчетами со стороны поставщика, недобросовестная конкуренция и т. д.

5 группа. Банкротство должника. Банкротство, как правило, возникает по экономическим причинам, вследствие наступления форс-мажорных обстоятельств или по неэкономическим причинам. Особую категорию составляет фиктивное банкротство, которое носит недобросовестный характер [1].

\section{Управление дебиторской задолженностью}

Для эффективного управления дебиторской задолженностью компании нужна всесторонняя информация о дебиторах и состоянии их расчетов. Получить необходимую для контроля информацию можно путем доработки системы бухгалтерского учета. Эффективность работы любой организации в первую очередь зависит от оперативности обработки документов, скорости распределения информации между подразделениями и контрагентами, а также от надежности всей информационной составляющей в целом.

Для управления дебиторской задолженностью необходима следующая информация:

- данные о выставленных дебиторам счетах, которые не оплачены на настоящий момент;

- время просрочки платежа по каждому из счетов;

- размер безнадежной и сомнительной дебиторской задолженности;

- кредитная история контрагента.

Управление дебиторской задолженностью начинается с организации правильного и своевременного документооборота внутри компании. Л. В. Путькина отмечает, что переход с бумажного документооборота на электронный должен быть грамотным и хорошо продуманным, т. к. от этого шага зависит дальнейшая работа всего предприятия [2].

Система комплексной автоматизации бизнеса, объединяющая все процессы и подразделения компании, должна включать следующие направления [3]:

- система электронного документооборота;

- управление бизнес-процессами;

- деловые коммуникации.

Процесс автоматизации документооборота включает несколько ключевых этапов. Первый этап - организация системы электронного документооборота, которая заключается в последовательном внедрении следующих блоков:

- электронное согласование договоров;

- электронный архив документов;

- электронное согласование прочих документов (локальных нормативных документов предприятия и т. п.);

- бюджетный контроль;

- контроль за своевременным закрытием документов.

Реализация блока электронного согласования договоров заключается в точном описании процедуры инициации, согласования, подписания, хранения, исполнения и закрытия договоров разных типов [4]. Согласованию договоров, проводимому в автоматизированном режиме, предшествует подготовительная работа, заключающаяся в категоризации договоров. Договоры с покупателями могут быть разделены по следующим категориям:

- по бизнес-процессам: продажи, закупки, маркетинг, администрирование, финансы, прочее [5];

- по типам: основной, срочный, дополнительное соглашение, спецификация;

- по статусу: подготовка договора, внутреннее согласование, на подписи у контрагента, действующий, закрыт.

Блок электронного согласования договоров позволяет исключить подмену договора при подписанном листе согласования, дает возможность контролировать сроки согласования договора.

Электронный документооборот предоставляет возможность осуществления работы с договорами в онлайн-режиме. При подготовке отчетности (после отчетной даты) специалисты видят не только все новые заключенные договоры, но и инициированные договоры в статусе подготовки или подписания [6]. Электронное согласование договоров является основным инструментом системы внутреннего контроля предприятия.

Электронный архив документов представляет собой хранилище сканов всех договоров и первичных документов. Целью данного блока системы электронного документооборота является обеспечение оперативного доступа к документам. Электронный архив позволяет оптимизировать работу бухгалтерской 
службы [4]. Работа с дебиторской задолженностью посредством электронного архива заключается в следующем:

- в результате обмена данными между структурными подразделениями в систему загружаются новые договоры с указанием статуса «действующий»; статусы же договоров, срок исполнения которых истек, изменяются на «приостановленный»;

- отражая новую бухгалтерскую операцию, бухгалтер обращается к договору, на основании которого эта операция проводится. Если указанного договора нет в системе (например, он еще не согласован) или его статус «просрочен», система не проведет данную операцию в учете;

- система связывает между собой такие бухгалтерские операции, как предоплата, принятие к учету материальных ценностей, курсовая разница, окончательная оплата и т. п.

Работа с документами из электронного архива позволяет сократить время на регистрацию факта хозяйственной деятельности в системе учета, своевременно исправлять ошибки, допущенные в учете.

Электронное согласование прочих документов призвано сократить сроки согласования локальных нормативных актов предприятия (инструкций, положений, стандартных процедур, регламентов и т. п.), а также обеспечить единое хранение этих документов и их версий [2].

Особый блок представляет бюджетный контроль, реализация которого напрямую связана с интеграцией данных между системами бюджетирования и электронного документооборота. Так как бюджетный контроль является элементом системы внутреннего контроля компании, его эффективное осуществление положительно влияет на оценку всей системы внутреннего контроля [7].

В организации, где внедрена система электронного документооборота, документ служит базовым инструментом управления, позволяет вносить релевантную информацию по договорам. Наиболее распространенными являются следующие данные:

- плановые и фактические платежи (заполняются по статьям управленческого отчета о движении денежных средств);

- плановое и фактическое предоставление закрывающих документов в разрезе сумм и сроков.

\section{Контроль уровня дебиторской задолженности}

Для большинства компаний актуален вопрос контроля за дебиторской задолженностью [3]. Задолженность покупателей можно контролировать по состоянию на отчетную дату (тогда отправной точкой анализа является просроченное сальдо контрагента) или на дату совершения оплаты (тог- да отправной точкой анализа являются неоплаченные вовремя отгрузки).

Внедрение системы электронного документооборота значительно расширяет возможности осуществления контрольных мероприятий за формированием дебиторской задолженности. Контроль становится возможен уже на этапе заключения договора, получения спецификации на отгрузку ${ }^{1}$. В СЭД поступает информация о фактических выплатах по договору и закрывающих документах, фиксируется информация о новых договорах и изменениях статуса старых, осуществляется реализация процесса контроля за исполнением договоров.

Работники бухгалтерской службы, ответственные за ведение документооборота, имеют возможность формировать отчет по договорам, период закрытия которых уже наступил, по договорам с неприкрепленными закрывающими документами, осуществляют работу с ответственными исполнителями [2].

Подводя итог вышесказанному, отметим, что основное преимущество, которое вносит система электронного документооборота в работу бухгалтерии, это удобство работы с первичной документацией. Второе преимущество - скорость обработки документов. Третье - отслеживание жизненного цикла любой транзакции. Бухгалтерская (финансовая) операция, отраженная в годовой отчетности компании, возникает на уровне планирования при бюджетировании, обретает форму через инициирование и подписание договора, материализуется фактически в виде передачи денег - получения товаров, работ, услуг - и наконец отражается в учете как двойная запись на бухгалтерских счетах [8].

Для обеспечения эффективной работы с дебиторской задолженностью необходимо своевременно реструктурировать и совершенствовать существующую систему работы организации. Системы автоматизированного управления бизнес-процессами пришли в Россию с Запада. Главной целью является осуществление программной поддержки процессного управления организацией [9]. Управление дебиторской задолженностью основано на моделировании бизнес-процессов компании с помощью наглядных диаграмм, что позволяет максимально сблизить реальное выполнение процесса с его идеальной моделью. Моделирование позволяет строить гибкие адаптивные информационные системы, способные оперативно меняться вместе с изменением бизнес-процессов компании, позволяет сделать их выполнение более четким [5].

Контроль за состоянием дебиторской задолженности в рамках выбранного бизнес-процесса может включать следующие направления:

\footnotetext{
${ }^{1}$ O формах бухгалтерской отчетности организаций. Приказ Минфина России от 02.07.2010 № 66н. Режим доступа: http:// //www. consultant.ru/document/cons_doc_LAW_103394/ (дата обращения: 15.10.2018).
} 
- формирование реестра старения дебиторской задолженности;

- мониторинг динамики основных показателей, характеризующих дебиторскую задолженность.

Формирование реестра дебиторской задолженности осуществляется в разрезе контрагентов или по направлениям деятельности. Составление такого реестра позволяет прогнозировать уровень дебиторской задолженности на будущий период и своевременно осуществлять его корректировку. Важным моментом в управлении дебиторской задолженностью является формирование базы информации о дебиторской задолженности и возможность ее анализа. Реестр старения дебиторской задолженности позволяет оценивать дебиторскую задолженность по различным «возрастным группам», определять уровень и состав «неблагополучной» или просроченной задолженности.

Автоматизированная система управления дебиторской задолженностью позволяет в любой момент времени получить информацию в разрезе каждого действующего договора с покупателем: заказы покупателей, обработка, статусы, резервирование товара, выставление счетов, печать накладных и актов выполненных работ, аналитические отчеты, акты сверки, регистрация платежей, в том числе в иностранной валюте, печать платежных поручений, кассовых ордеров. Также в системе могут быть оперативно подготовлены отчеты по взаиморасчетам, движению денежных средств, выручке от продажи товаров, работ или услуг [10].

\section{Заключение}

Деловые коммуникации определяют цель и задачи, решение которых необходимо для их достижения. К средствам электронной коммуникации, используемым в деловом общении, относятся: факсимильная связь, телефон и мобильный телефон, электронная почта, видеоконференции, селекторная связь, телемосты, Интернет. Использование современных технологий способствует эффективному управлению клиентской базой, позволяет повысить эффективность от присутствия бизнеса в Интернете. Важное значение отводится эффективному управлению клиентской базой, распределению функций и полномочий между работниками, ведущими работу с дебиторской задолженностью (клиент - сотрудник, сотрудник - сотрудник, личное - рабочее). Грамотная автоматизация бизнес-процессов является гарантией эффективности всех осуществляемых мероприятий.

\section{Литература}

1. Павлюченко Т. Н. Учет выручки по договорам с покупателями // Вестник Воронежского государственного аграрного университета. 2017. № 1. С. 232-242.

2. Путькина Л. В. Особенности внедрения электронного документооборота // Nauka-rastudent.ru. 2016. № 07(031). Режим доступа: http://nauka-rastudent.ru/31/3586/ (дата обращения: 15.10.2018).

3. Копытина М. Л., Воробьев С. В., Бунина А. Ю. Бюджетирование, как эффективный инструмент управления предприятием // Экономика и предпринимательство. 2016. № 1-2. С. 664-667.

4. Павлюченко Т. Н. Электронный документооборот как средство управления предприятием // Управленческие и маркетинговые аспекты развития субъектов АПК и агропродовольственного рынка: материалы межрегион. науч.-практ. конф., посвященной 45-летию кафедры управления и маркетинга в АПК (Воронеж, 09-11 ноября 2016 г.). Воронеж, 2016. С. 209-212.

5. Лубков В. А., Коваленко Е. В., Путилина О. О. Бизнес модель - базовая единица стратегического анализа // Политэкономические проблемы развития современных агроэкономических систем: материалы 2-й междунар. науч.-практич. конф., посвященной 105-летию Воронежского ГАУ (Воронеж, 29 марта 2017 г.). Воронеж, 2017. С. 63-65.

6. Кузнецова И. В., Волкова Н. Н. Проблемы раскрытия информации об оценочных обязательствах в бухгалтерской отчетности организации // Проблемы экономики, организации и управления в России и мире: материалы междунар. науч.-практ. конф. (Прага, 28 декабря 2012 г.). 2013. С. 55-61.

7. Широбоков В. Г. Вектор развития активно-адаптивной системы бухгалтерского учета в агропромышленном комплексе // Международный бухгалтерский учет. 2012. № 31. С. 3-9.

8. Кузнецова И. В., Галикова Н. Б. Оценочные обязательства в бухгалтерском учете сельскохозяйственных организаций // Апрельские научные чтения имени профессора Л. Т. Гиляровской: материалы междунар. науч.-практ. конф. (Воронеж, 13 апреля 2012 г.). В 2-х ч. 2012. Ч. 1. С. 78-80.

9. Воробьев С. В., Воронкова В. В. Автоматизация бухгалтерского учета в аграрных формированиях // Территория науки. 2008. № 8. С. 55-60.

10. Журкина Т. А., Кумарина Э. Г. Оборотные активы предприятия и их анализ // Инструменты и механизмы современного инновационного развития: сб. ст. междунар. науч.-практ. конф. (Волгоград, 5 сентября 2016 г.). Уфа, 2016. С. 67-70. 


\title{
ORGANIZATION OF ELECTRONIC DOCUMENT MANAGEMENT FOR RECEIVABLES MANAGEMENT
}

Tatyana N. Pavlyuchenko ${ }^{a,{ }^{a}, I D}$; Irina V. Kalyugina ${ }^{a}$

\author{
${ }^{a}$ Emperor Peter I Voronezh State Agrarian University, 1, Michurin st., Voronezh, Russia, 394087 \\ @Pavlychenko_tn@mail.ru \\ ID https://orcid.org/0000-0002-9879-1079
}

Received 03.11.2018. Accepted 26.11.2018.

\section{Keywords:}

business process, control, accounting Department, electronic archive, business communications

\begin{abstract}
The priority goal of most companies in the process of formation of financial data on the availability and movement of accounts receivable is to reduce its time with no loss of quality. The goal can be achieved by the optimization of business processes. One of its directions can be electronic document management. The introduction of electronic document management will significantly reduce the processing of contracts, while ensuring acceptable completeness and reliability of information. An automatically generated daily report makes it possible to control receivables and respond to overdue debts. The article considers the process of implementation of the electronic document management system and emphasizes the effectiveness and feasibility of its use in the preparation of information on debtors accounts. One of the key circumstances is that after successful completion of all stages of automation, the implemented system should be constantly refined and improved. This is a major factor in the successful use of electronic document management for receivables management.
\end{abstract}

For citation: Pavlyuchenko T. N., Kalyugina I. V. Organizatsiia elektronnogo dokumentooborota dlia upravleniia debitorskoi zadolzhennost'iu [Organization of Electronic Document Management for Receivables Management]. Bulletin of Kemerovo State University. Series: Political, Sociological and Economic Sciences, no. 4 (2018): 107-112. DOI: 10.21603/2500-3372-2018-4-107-112

\section{References}

1. Pavlyuchenko T. N. Uchet vyruchki po dogovoram s pokupateliami [Accounting for revenues from contracts with customers]. Vestnik Voronezhskogo gosudarstvennogo agrarnogo universiteta = Vestnik of Voronezh state agrarian university, no. 1 (2017): 232-242.

2. Put'kina L. V. Osobennosti vnedreniia elektronnogo dokumentooborota [Features of the implementation of electronic document management]. Nauka-rastudent.ru, no. 07(031) (2016). Available at: http://naukarastudent.ru/31/3586/ (accessed 15.10.2018).

3. Kopytina M. L., Vorobyov S. V., Bunina A. Iu. Biudzhetirovanie, kak effektivnyi instrument upravleniia predpriiatiem [Budgeting as an effective tool of enterprise management]. Ekonomika i predprinimatel'stvo = Journal of Economy and Entrepreneurship, no. 1-2 (2016): 664-667.

4. Pavliuchenko T. N. Elektronnyi dokumentooborot kak sredstvo upravleniia predpriiatiem [Electronic document management as a means of enterprise management]. Upravlencheskie $i$ marketingovye aspekty razvitiia sub"ektov APK $i$ agroprodovol'stvennogo rynka: materialy mezhregion. nauch.-prakt. konf., posviashchennoi 45-letiiu kafedry upravleniia i marketinga v APK (Voronezh, 09-11 noiabria 2016 g.) [Management and marketing aspects of the development of subjects of the agro-industrial complex and the agrifood market: Proc. Sci.-Prac. Conf., dedicated to the 45th anniversary of the Department of Management and Marketing in the AIC (Voronezh, November 9-11, 2016)]. Voronezh, 2016, 209-212.

5. Lubkov V. A., Kovalenko E. V., Putilina O. O. Biznes model' - bazovaia edinitsa strategicheskogo analiza [The business model is the basic unit of strategic analysis]. Politekonomicheskie problemy razvitiia sovremennykh agroekonomicheskikh sistem: materialy 2-i mezhdunar. nauch.-praktich. konf., posviashchennoi 105-letiiu Voronezhskogo GAU (Voronezh, 29 marta 2017 g.) [Political Economic Problems of the Development of Modern Agro-Economic Systems: Proc. 2nd Intern. Sci.-Prac. Conf., dedicated to the 105th anniversary of the Voronezh State Agrarian University (Voronezh, March 29, 2017)]. Voronezh, 2017, 63-65.

6. Kuznetsova I. V., Volkova N. N. Problemy raskrytiia informatsii ob otsenochnykh obiazatel'stvakh $\mathrm{v}$ bukhgalterskoi otchetnosti organizatsii [Problems of disclosure of information on estimated liabilities in the financial statements of an organization]. Problemy ekonomiki, organizatsii i upravleniia v Rossii i mire: materialy 
mezhdunar. nauch.-prakt. konf. (Praga, 28 dekabria 2012 g.) [Problems of economics, organization and management in Russia and the world: Proc. Intern. Sci.-Prac. Conf. (Prague, December 28, 2012)]. 2013, 55-61.

7. Shirobokov V. G. Vektor razvitiia aktivno-adaptivnoi sistemy bukhgalterskogo ucheta v agropromyshlennom komplekse [The vector of development of an actively-adaptive accounting system in the agro-industrial complex]. Mezhdunarodnyi bukhgalterskii uchet = International Accounting, no. 31 (2012): 3-9.

8. Kuznetsova I. V., Galikova N. B. Otsenochnye obiazatel'stva v bukhgalterskom uchete sel'skokhoziaistvennykh organizatsii [Estimated liabilities in the accounting of agricultural organizations]. Aprel'skie nauchnye chteniia imeni professora L. T. Giliarovskoi: materialy mezhdunar. nauch.-prakt. konf. (Voronezh, 13 aprelia 2012 g.) [April scientific readings named after professor L. T. Gilyarovskaya: Proc. Intern. Sci.-Prac. Conf. (Voronezh, April 13, 2012)]. Part 1 (2012): 78-80.

9. Vorob'ev S. V., Voronkova V. V. Avtomatizatsiia bukhgalterskogo ucheta v agrarnykh formirovaniiakh [Automation of accounting in agrarian formations]. Territoriia nauki = Science Territory, no. 8 (2008): 55-60.

10. Zhurkina T. A., Kumarina E. G. Oborotnye aktivy predpriiatiia i ikh analiz [Current assets of an enterprise and their analysis]. Instrumenty $i$ mekhanizmy sovremennogo innovatsionnogo razvitiia: sb. st. mezhdunar. nauch.-prakt. konf. (Volgograd, 5 sentiabria 2016 g.) [Tools and mechanisms for modern innovation development: Proc. Intern. Sci.-Prac. Conf. (Volgograd, September 5, 2016)]. Ufa, 2016, 67-70. 